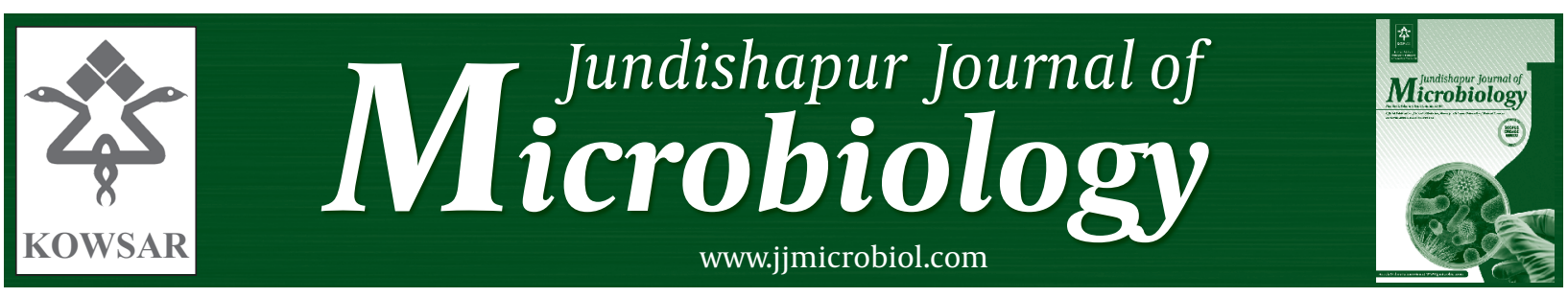

\title{
Nocturnal Activity, Monthly Leptomonad Infection, Parity Rate and Physiological Status Vectors of Zoonotic Cutaneous Leishmaniasis (Diptera: Psychodidae) in Southeastern Iran
}

\author{
Hamid Kassiri ${ }^{1 *}$, Ahmad Ali Hanafi-Bojd ${ }^{2}$, Ezzatoddin Javadian ${ }^{2}$ \\ ${ }^{1}$ Department of Medical Entomology and Vector Control, School of Health, Ahvaz Jundishapur University of Medical Sciences, Ahvaz, IR Iran \\ ${ }^{2}$ Department of Medical Entomology \& Vector Control, School of Public Health, Tehran University of Medical Sciences, Tehran, IR Iran
}

\section{A R T I C L E I N F O}

Article type:

Original Article

Article history:

Received:12 May 2012

Revised:14 May 2012

Accepted: 15 May 2012

Keywords:

Phlebotomus papatasi

Phlebotomus salehi

Leptomonad Infection

Nocturnal Activity

\begin{abstract}
A B S T R A C T
Background: Phlebotomus papatasi and P. salehi are reported as vectors of cutaneous leishmaniasis in southeast of Iran. Seasonal activity of these species is different in zoogeographical zones and must be known well for better management of the disease. Objectives: To determine the nocturnal activity of sand flies and their leptomonad infection rates.

Materials and Methods: A cross-sectional study was carried out in Chabahar county, where sand flies were collected using sticky-paper traps at 2 - hours intervals from rodent burrows during May to October. Females of Phlebotomus spp. were dissected for leptomonad infection.

Results: A total of 9367 sand flies from four species of Phlebotomus and Sergentomyia genera were collected. The most sand flies were collected in the first third of the night (7:0011:00 PM), although there was seasonal variation in the nocturnal activity of different species. A total of 1132 female sand flies from two species of P. papatasi and P. salehi were dissected. Totally $2.1 \%$ of P. papatasi and $1.07 \%$ of P. salehi were found to have leptomonad infection in their midgut, pharynx or head. The infection was observed in September and October in P. salehi, but June, August, September and October for P. papatasi.

Conclusions: Knowledge about nocturnal activity and biting rhythms of sand flies and therefore the risk of disease transmission is important for planning control programs for cutaneous leishmaniasis(CL).
\end{abstract}

Published by Kowsar Corp, 2013. cc 3.0.

- Implication for health policy/practice/research/medical education:

Decision makers in health system can do their best for control of vector-borne diseases, when different particles of transmission puzzle are defined. An important particle in the case of cutaneous leishmaniasis in the study area is clarified which helps for better managing control programs.

Please cite this paper as:

Kassiri H, Hanafi-Bojd AA, Javadian E. Nocturnal Activity, Monthly Leptomonad Infection, Parity Rate and Physiological Status Vectors of Zoonotic Cutaneous Leishmaniasis (Diptera: Psychodidae) in Southeastern Iran. Jundishapur J Microbiol. 2013;6(1):51-6. DOI: $10.5812 / j j m .6322$

\footnotetext{
${ }^{*}$ Corresponding author: Hamid Kassiri, Medical Entomology and Vector Control, School of Health, Ahvaz Jundishapur University of Medical Sciences, Ahvaz, IR Iran.Tel:+98-6113738296, Fax:+98-6113738282,E-mail: Hamid.kassiri@yahoo.com

DOI: $10.5812 / j \mathrm{jm} .6322$

(C) 2013 Ahvaz Jundishapur University of Medical Sciences; Published by Kowsar Corp.

This is an Open Access article distributed under the terms of the Creative Commons Attribution License (http://creativecommons.org/licenses/by/3.0), which permits unrestricted use, distribution, and reproduction in any medium, provided the original work is properly cited.
} 


\section{Background}

Leishmaniasis is an important public health problem in the world. The disease have cutaneous and visceral forms in Iran (1). Phlebotomine sand flies (Diptera: Psychodidae) are introduced as vectors of leishmaniasis (2). There is a list of 54 reported species from the country (3), some of them have been found to be infected with Leishmania spp. Phlebotomus papatasi, P. salehi, P. sergenti and P. caucasicus group are reported as vectors of cutaneous leishmaniasis in Iran, although the last one is responsible to circulate the infection in the rodent population (4-13).

Chabahar county is a focus of cutaneous leishmaniasis in southeast of Iran. There are some studies on the disease and sand flies fauna of this area $(14,15)$. Because the nocturnal activity of sand flies and therefore their biting times has a critical role in the disease transmission and planning the control programs as well, this study was conducted to answer some questions in this field.

\section{Objectives}

This study aimed to determine the seasonal fluctuation of leptomonads infection in sand flies, their nocturnal activity in the study area, their physiological age during the study period and the seasonal changes in age groups of sand flies in Chabahar county, Sistan Va Baluchistan province, Southeastern of Iran.

\section{Materials and Methods}

\subsection{Study Area}

Chabahar county $\left(25^{\circ} 17^{\prime} 31^{\prime \prime} \mathrm{N}, 60^{\circ} 38^{\prime} 35^{\prime \prime} \mathrm{E}\right)$ is situated on the Makran coast of the Sistan Va Baluchistan province of Iran, $9 \mathrm{~m}$ above the sea level, and is officially designated as a Free Trade and Industrial Zone by Iran's government. The county has a warm humid weather in the summer and a temperate weather in the winter (Statistical Center of Iran and Iran Meteorological Organization). It has an average maximum temperature of $34^{\circ} \mathrm{C}$ and an average minimum temperature of $10.5^{\circ} \mathrm{C}$. Chabahar County is subdivided into three districts, has two cities and 592 inhabited villages (Statistical Center of Iran and Iran Meteorological Organization)

\subsection{Nocturnal Activity of Sand flies}

Considering the importance of biting times of sand flies and therefore the probable times of the parasite transmission, sand flies were collected by sticky paper traps from the rodent burrows during May to October in Polan village (Figure 1). Trapping was conducted once a month at two hours intervals, from 7:00 PM till 7:00 AM of the next day. The number of traps for each interval was 15 and they were changed every 2 hours. The attached sand flies were removed by needle, washed in acetone and then conserved in ethanol 70\%. In the laboratory the permanent mounts were prepared using Puri's medium and identified by the relevant keys of sand flies (16). Sex ratio, (i.e. the rate of males per 100 females) was calculated for all species.

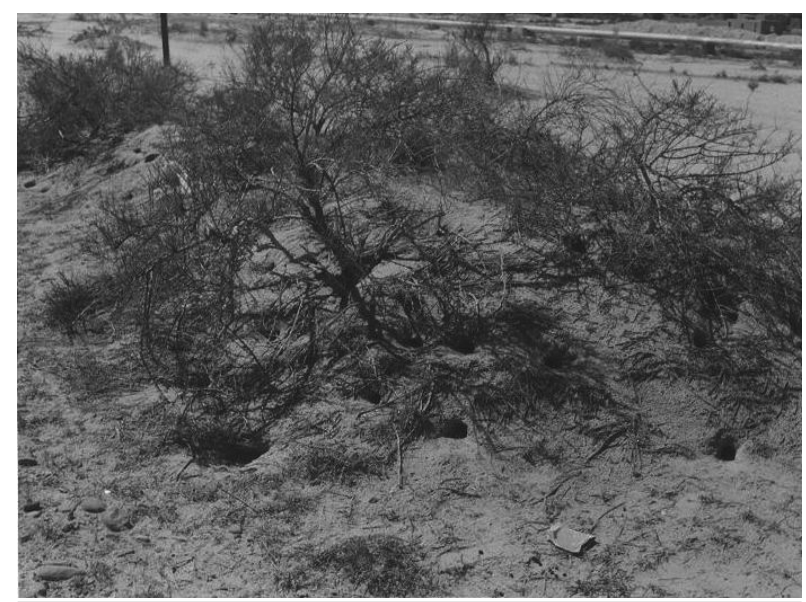

Figure 1. A View of Rodent Burrows in the Study Area, Southeast of Iran

\subsection{Physiological Age, Leptomonad Infection Rates and Parity Status}

During June to October, sand flies were collected from rodent burrows of Negor, Polan and Nobandian villages by using sticky paper traps. Females were dissected for leptomonad infection in their head and midgut. Giemsa staining was used for staining of the positive slides, and then they were examined under light-microscope using $40 X$ and $100 X$ objectives. During the dissection, accessory glands were observed for parity status of sand flies, while abdominal status was also considered and recorded as unfed, blood-fed, semi-gravid and gravid.

\section{Results}

A total of 9367 sand flies were collected from the Polan village. Males (55\%) were more than females (45\%). Four species were identified as P. papatasi (47.9\%), P. salehi (6.8\%), Sergentomyia clydei (40\%) and S. sintoni (5.3\%). The total peak of activity was found to be at 7:00 to9:00 PM while only in August it was at 1:00 to 3:00 AM (Figure 2).

Sex ratio was $157.5,110.3,112.2$ and 23.7 for P. papatasi, $P$.

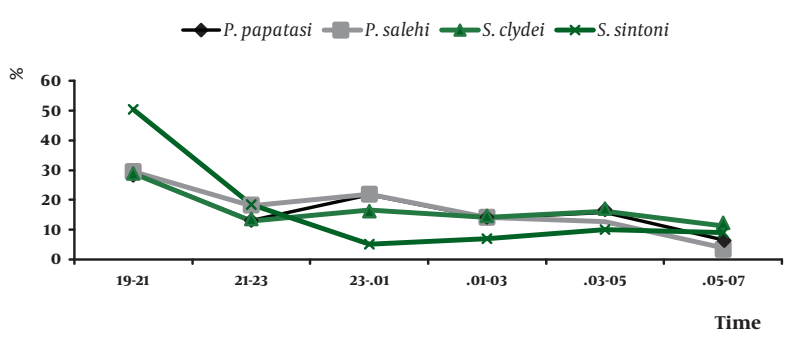

Figure 2. Nocturnal Activity of Collected Sand flies in Polan Village, Chabahar district, Southeastern Iran 


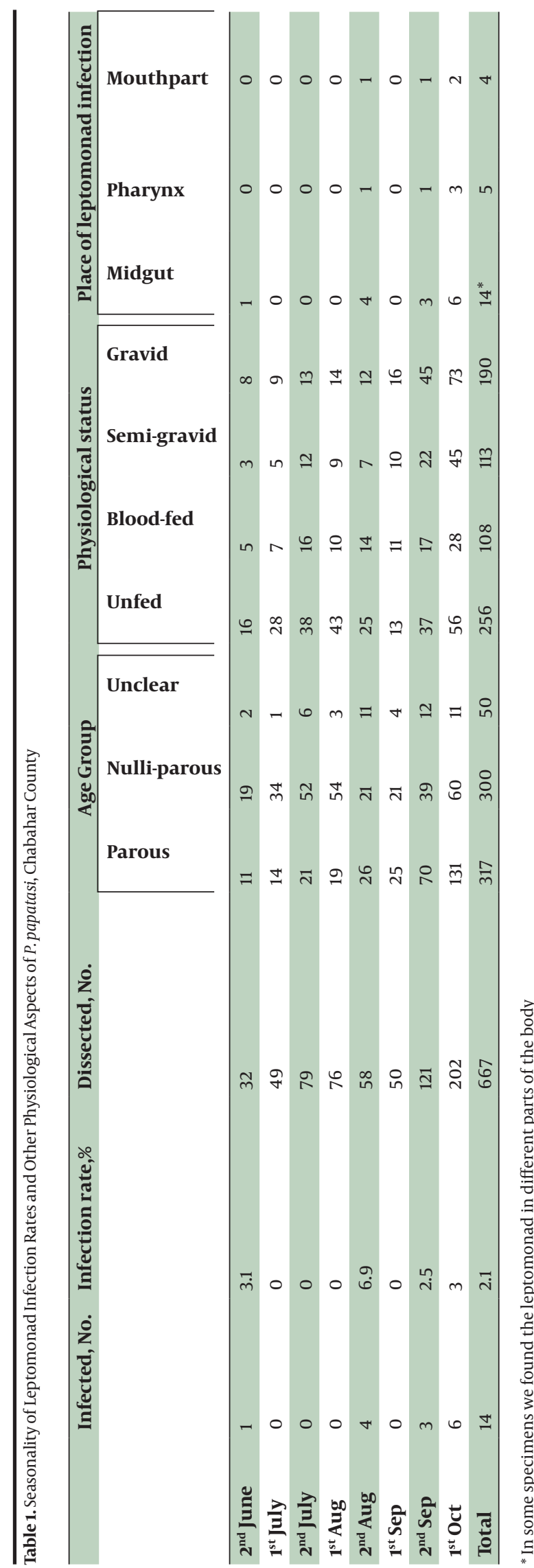

salehi, S. clydei and S. sintoni, respectively. During the first third of the night (7:00 to11:00 PM) 43.7\% of sand flies were collected (57.5\% male, $42.5 \%$ female). This value was $35.5 \%$ (56.2\% male, $43.8 \%$ female) for the second third and $23.8 \%$ (48.8\% male, 51.2\% female) for the last third of the night. The majority of sand flies for each species were collected in the first third of the nigh (7:00 to11:00 PM), followed by the second (11:00 PM-3:00 AM) and last thirds (3:00-7:00 AM). Only one exception observed about $S$. sintoni, where the number of collected specimens in the last third of the night was higher than the second one.

A total of 1132 female sand flies belonged to genus Phlebotomus were collected from Negor, Polan and Nobandian villages, and dissected for leptomonad infection; $41.1 \%$ were P. salehi and $58.9 \%$ P. papatasi (Figure 3). In the case of $P$. papatasi $47.5 \%$ were parous, $44.9 \%$ nulliparous, also the physiological age of $7.6 \%$ was not clear (Table 1 ). The analysis of physiological status of dissected $P$. papatasi revealed $38.4 \%$ unfed, $16.2 \%$ blood-fed, $16.9 \%$ semi-gravid and $28.4 \%$ gravid. The highest rate of gravid and parous P. papatasi was collected in first half of October (Table 1). In P. salehi the parity rate was as follow: $53.3 \%$ parous, $39.4 \%$ nulliparous and $7.3 \%$ unclear. The physiological status of this species showed 50.9\% unfed, 9.9\% blood-fed, $8.4 \%$ semi-gravid and $30.8 \%$ gravid (Table 2). About the $P$. salehi gravidity and parity rates were found to be highest in first half of October (Table 2).

Totally $2.1 \%$ of 667 dissected P. papatasi were found to be infected with leptomonad flagellates of Leishmania spp (Table 1). This rate was $1.07 \%$ out of 456 for P. salehi (Table $2)$. The infection rate was observed in first and second halves of September $(1.8 \%, 3.3 \%)$ and also October (0.6\%) in P. salehi, but about P. papatasi were 3.1\%, 6.9\%, 2.5\% and 3\%, in June, August, September and October respectively.

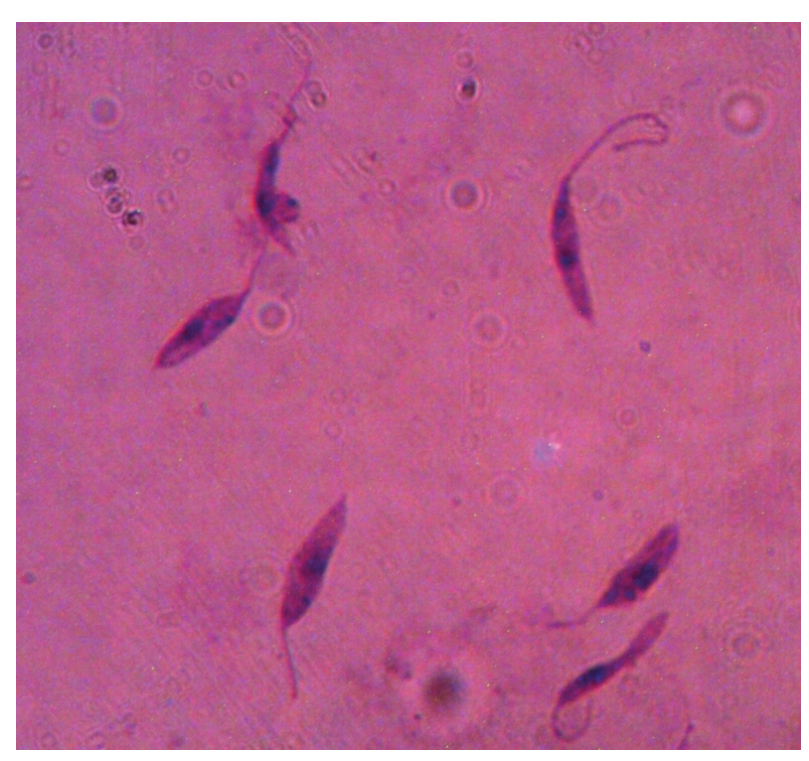

Figure 3. Leptomonad Infection in Sand flies of Chabahr District, Southeast of Iran 


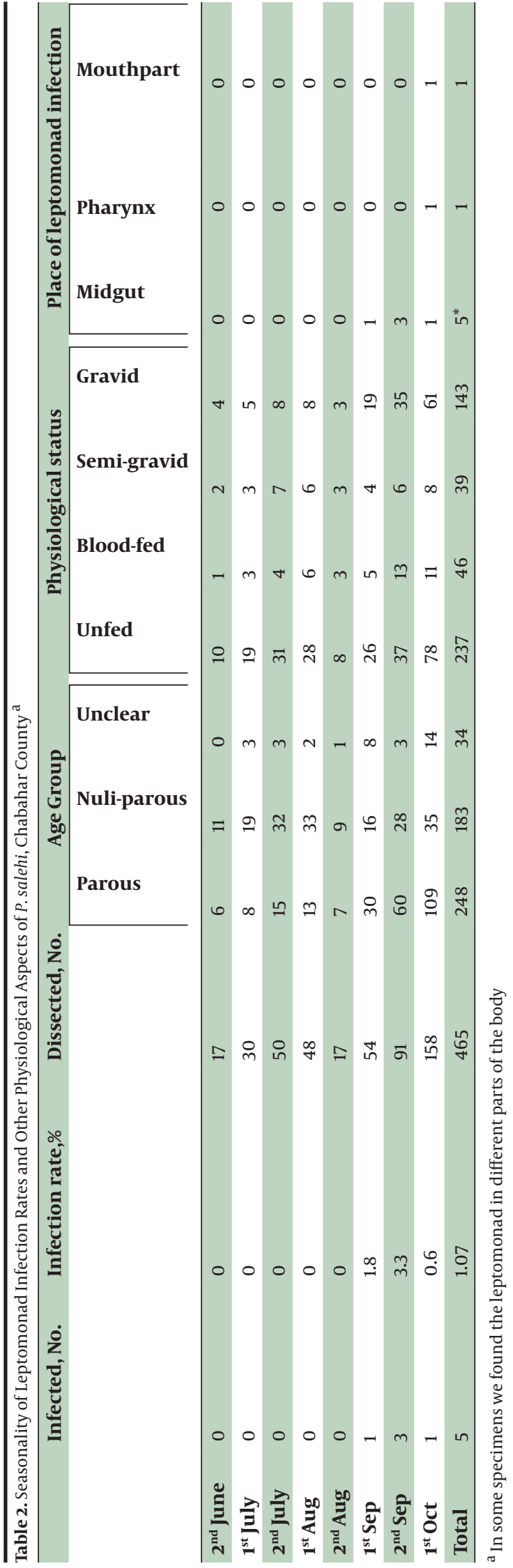

\section{Discussion}

There is a global estimate of 12 million leishmaniasis cases with 2 million new annual events and a population of 350 million at risk of the disease (17). Cutaneous leishmaniasis is a major public health problem in arid and semiarid zones of the Middle East, northern Africa and Central Asia (18). Although four types of leishmaniasis including cutaneous and visceral forms exist in the Middle East, whereas the cutanoeus form (CL) is the most common. Middle East and Maghreb countries harbour are attributed to approximately $15 \%$ of the global leishmaniasis burden, which is almost exclusively attributable to CL (19).

Unfortunately the cases of CL, especially zoonotic form of the disease caused by Leishmania major have reported from 17 out of 31 provinces of the country (7). Based on the reports of leishmaniasis unit of CDC, ministry of health, during the previous decade (2001-2010) a total of 228725 cases of CL were reported from different foci of the disease in Iran, out of them 2.5\% was discovered in Sistan and Baluchistan province (Personal communication). Besides the cessation of indoor residual spraying for malaria control in most parts of Iran, other reasons for the increasing trend of CL in Iran, seems to be the unplanned growth and development of urban areas as well as human made changes in ecosystem, which has resulted in close contacts of human to zoonotic cycle of the disease( i.e. gerbil colonies) (20).

Cutaneous leishmaniasis has been emerged during recent years in rural areas of Mirjaveh district, Sistan and Baluchistan province in Southeast of Iran (21). This area is close to boundaries of Iran and Afghanistan, although the disease has been reported from Chabahar and Konarak as well (13). Therefore the study on biology and ecology of sand flies, as the vectors of cutaneous leishmaniasis, is important.

During this study two proven vectors of zoonotic cutaneous leishmaniasis (ZCL) in Iran, i.e. P. papatasi and $P$. salehi were collected, which were infected with leptomonad. Parous, gravid and semi-gravid of these species were increased toward the end of seasonal activity during September and October for $P$. papatasi with total infection rate of $2.1 \%$. During these months the condition of temperature and relative humidity is appropriate for the sand flies which also increases their longevity. Therefore the probability of leptomonad infection and disease transmission increase among the old sand flies. The same trend of infection is reported from north Siani in Egypt $(22,23)$. P. papatasi is introduced as ZCL vector in Chabahar county $(13,24)$. The same trend of parity and physiological status was observed for P. salehi with a total infection rate of $1.07 \%$. This species is also introduced as ZCL vector in Chabahar county $(13,24)$.

The most nocturnal activity for all species occured during 19:00 to21:00, while P. papatasi and P. salehi had another peak of activity in midnight (23:00 too0:01). The 
pattern reported from Turkey had an increasing trend from sunset to midnight for this species (25), while study in Morocco represented a decreasing trend for P. papatasi from 19:00 to next morning (26). Some studies reporm ted two peaks of activity, it means for instance, in Saudi Arabia the first peak observed in 21:00 to22:00 and the second in 06:00 to07:00 (27), while in Palestine the first and second peaks recorded at 22:00 to24:00 and 00:02 to00:04, respectively (28).

In conclusion, inhabitants of the study area are in a great risk of sand flies bites. Undrestanding the nocturnal activity of these insects and their biting habits improves the ability of health authorities to plan for reducing contacts between sand flies and human that will result in better prevention and control of CL transmission. Based on all mentioned studies and our findings as well, sand flies usually start their host seeking behavior soon after sunset. During this time people are mostly active and therefore prevention of contact with sand flies is possible only by using repellents. But in the second peak of nocturnal activity, most of people are sleep and so longlasting insecticide treated nets (LLINs) can help to better prevention and control of cutaneous leishmaniasis.

\section{Acknowledments}

The authors would like to thank the personnel of Iranshahr health research station, National Institute of Health Research and Chabahar health services centre for their kind collaboration during the survey.

\section{Financial Disclosure}

None declared.

\section{Funding/Support}

This project is funded by deputy of research, School of Public Health, Tehran University of Medical Sciences.

\section{Authors' Contribution}

None declared.

\section{References}

1. Postigo JA. Leishmaniasis in the World Health Organization Eastern Mediterranean Region. Int J Antimicrob Agents. 2010;36 Suppl 1:S62-5.

2. Killick-Kendrick R. The biology and control of phlebotomine sand flies. Clin Dermatol.1999;17(3):279-89.

3. Kasiri H, Javadian E, Seyedi-Rashti MA. [List of Phlebotominae (Diptera:Psychodidae) of Iran]. Bull Soc Pathol Exot. 2000;93(2):129-30.

4. Yaghoobi-Ershadi MR, Akhavan AA. Entomological survey of sandflies (Diptera: Psychodidae) in a new focus of zoonotic cutaneous leishmaniosis in Iran. Acta Trop.1999;73(3):321-6.

5. Yaghoobi-Ershadi MR, Akhavan AA, Zahraei-Ramazani AR, JalaliZand AR, Piazak N. Bionomics of Phlebotomus papatasi (Diptera: Psychodidae) in an endemic focus of zoonotic cutaneous leishmaniasis in central Iran. J Vector Ecol. 2005;30(1):115-8.

6. Yaghoobi-Ershadi MR, Akhavan AA, Zahraei-Ramazani AV, Abai
MR, Ebrahimi B, Vafaei-Nezhad R, et al. Epidemiological study in a new focus of cutaneous leishmaniasis in the Islamic Republic of Iran. East Mediterr Health J. 2003;9(4):816-26.

7. Yaghoobi-Ershadi MR, Hakimiparizi M,Zahraei-Ramazani AR, Abdoli H, Akhavan AA, Aghasi M, et al. Sand fly surveillance within an emerging epidemic focus of cutaneous leishmaniasis in southeastern Iran. Iranian J Arthropod-Borne Dis. 2010;4(1):17-23.

8. Yaghoobi-Ershadi MR, Javadian E. Seasonal variation of Leishmania major infection rates in sandflies from rodent burrows in Isfahan province, Iran. Med Vet Entomol.1996;10(2):181-4.

9. Yaghoobi-Ershadi MR, Javadian E, Tahvildare-Bidruni GH. The isolation of Leishmania major from Phlebotomus (Paraphlebotomus) caucasicus, in Isfahan province, Islamic Republic of Iran. Trans R Soc Trop Med Hyg. 1994;88(5):518-9.

10. Yaghoobi-Ershadi MR, Javadian E, Tahvildare-Bidruni GH. Leishmania major MON-26 isolated from naturally infected Phlebotomus papatasi (Diptera: Psychodidae) in Isfahan Province, Iran. Acta Trop. 1995;59(4):279-82.

11. Abdoli H, Hejazi SH, Akhavan AA, Zahraei-Ramazani AR, YaghoobiErshadi MR, Jalali-Zand AR, et al. Some Ecological Aspects of Phlebotomine Sand Flies in an Endemic Focus of Cutaneous Leishmaniasis in Iran. Iranian J Arthropod-Borne Dis. 2007;1(2):34-9.

12. Azizi K, Rassi Y, Moemenbellah-Fard MD. PCR-based detection of Leishmania major kDNA within naturally infected Phlebotomus papatasi in southern Iran. Trans R Soc Trop Med Hyg. 2010;104(6):440-2.

13. Kasiri H, Javadian E. The natural leptomonad infection of Phlebotomus papatasi and Phlebotomus salehi in endemic foci of cutaneous leishmaniasis in Sistan and Baluchistan province (Southeast of Iran). Iranian J Public Health. 2000;29(1-4):15-20.

14. Kassiri H, Javadian E, Hanafi-Boj AA. Species composition of Phlebotomine sandflies (Diptera: Psychodidae) in Nikshahr county, south -eastern Iran. J Vector Borne Dis. 2011;48(3):159-62.

15. Kassiri H, Javadian E, Hanafi-Bojd AA. Faunistic survey of sand flies (Diptera: Psychodidae) in Chabahar County, Southeast of Iran. J Experimental Zool India. 2011;14(2):663-66.

16. Theodor O, Mesghali A. On the Phlebotominae of Iran.J Med Entomol.1964;1:285-300.

17. Desjeux P. The increase in risk factors for leishmaniasis worldwide. Trans R Soc Trop Med Hyg. 2001;95(3):239-43.

18. Ashford RW. Leishmaniasis reservoirs and their significance in control. Clin Dermatol.1996;14(5):523-32.

19. WHO. Report of the consultative meeting on cutaneous leishmaniasis. 2008.

20. Nadim A, Javadian E, Mohebali M, Zamen Momeni A. The Leishmania parasite and Leishmaniasis. Markaze Nashre Daneshgahi Publ. 2008:288 pp.

21. Fazaeli A, Fouladi B, Hashemi-Shahri SM, Sharifi I. Clinical Features of Cutaneous Leishmaniasis and Direct PCR-Based Identification of Parasite Species in A New Focus in Southeast of Iran. Iranian J Publ Health. 2008;37(3):44-51.

22. Fahmy AR, Samy AM, Doha SA, Shehata MG. Preliminary field investigations on Phlebotomine sandflies (Diptera: Psychodidae) from a recent cutaneous leishmaniasis focus in Northern-Sinai, Egypt. Egypt Acad Biolog Sci. 2009;2(1):9 - 15.

23. Hanafi HA, Fryauff DJ, Modi GB, Ibrahim MO, Main AJ. Bionomics of phlebotomine sandflies at a peacekeeping duty site in the north of Sinai, Egypt. Acta Trop. 2007;101(2):106-14.

24. Kassiri H, Naddaf SR, Mohebali M, Javadian EA. Molecular Characterization of Leishmania Infection in Sand flies From Sistan Va Baluchistan Province, Southeastern Iran. Jundishapur J Microbiol. 2012;5(2):430-1.

25. Kasap OE, Belen A, Kaynas S, Simsek FM, Biler L, Ata N, et al. Activity Patterns of Sand Fly (Diptera: Psychodidae) Species and Comparative Performance of Different Traps in an Endemic Cutaneous Leishmaniasis Focus in Cukurova Plain, Southern Anatolia, Turkey. Acta Veterinaria Brno. 2009;78(2):327-35.

26. Guernaoui S, Boussaa S, Pesson B, Boumezzough A. Nocturnal activity of phlebotomine sandflies (Diptera: Psychodidae) in a cutaneous leishmaniasis focus in Chichaoua, Morocco. Parasitol Res. 2006;98(3):184-8. 
27. EI-Badry AA, Eassa AHA, Ibrahim E-K. Nocturnal activity and biting rhythm of sand flies (Diptera; Psychodidae) in AI-Agool, AlMadinah AI-Munawarah, Saudi Arabia. Parasitologists United J. 2008;1(2):93-100.
28. Sawalha SS, Shtayeh MS, Khanfar HM, Warburg A, Abdeen ZA Phlebotomine sand flies (Diptera: Psychodidae) of the Palestinian West Bank: potential vectors of leishmaniasis. J Med Entomol. 2003;40(3):321-8. 